\title{
STRUCTURAL EVALUATION OF TYPICAL HISTORICAL MASONRY VAULTS OF CAGLIARI: SENSITIVITY TO BRICKS ARRANGEMENTS
}

\author{
A. CAZZANi ${ }^{1}$, N. GRILlANDA ${ }^{2}$, G. MILANI ${ }^{2}$, V. PINTUS ${ }^{1}$ AND E. RECCIA $^{1 *}$ \\ ${ }^{1}$ Department of Civil and Environmental Engineering and Architecture (DICAAR) \\ University of Cagliari, Via Marengo 2, 09123 Cagliari, Italy \\ email: emanuele.reccia@unica.it (*corresponding author) \\ e-mail: \{antonio.cazzani, valentinapintus\}@unica.it \\ ${ }^{2}$ Department of Architecture, Built Environment and Construction Engineering (A., B., C.) \\ Politecnico di Milano, Piazza Leonardo da Vinci 32, 20133 Milan, Italy \\ e-mail: \{nicola.grillanda, gabriele.milani\}@polimi.it
}

Keywords: Masonry Vaults, Limit Analysis, NURBS, Genetic Algorithm, Laser Scanner Survey, Conservation

\begin{abstract}
Masonry vaults have a great diffusion in the historical architectural heritage: in this work, their structural behavior is investigated. Attention is focused on lowered sail vaults composed by several brick arrangements, a typical nineteenth-century masonry vault which have great diffusion in Cagliari (Sardinia). The target is evaluating the role played by bricks arrangement in their mechanical behavior. A series of rigorous laser scanner surveys have been performed in order to obtain the effective geometry both at macro-level the vault shape - and at micro-level - brick patterns. A NURBS (Non-Uniform Rational BSpline) representation of the geometry is adopted and adaptive upper bound limit analyses are performed. NURBS entities, which are common in commercial CAD packages, have the great advantage to describe complex geometries such as curved elements, with very few elements. An upper bound limit analysis formulation is adopted, in which the NURBS elements forming the mesh are idealized as rigid bodies with dissipation allowed only along interfaces. The mesh constituted by few NURBS elements is progressively adjusted through a genetic algorithm in order to minimize the live load multiplier. Limit analysis is performed initially to determine the collapse multiplier of vertical loads, to assess the load bearing capacity of the vault, then attention is focused on differential settlements, that may be a serious hazard for this structural typology.
\end{abstract}

\section{INTRODUCTION}

Masonry is an ancient structural material and it constitutes most of the historical architectural heritage. It is a composite and heterogeneous material obtained by the assemblage of natural or artificial blocks by means of mortar layers or dry joints. Its internal structure reflects in a complex mechanical behavior, whose understanding represents a challenging research field. During last decades several numerical approaches have been developed: a significant classification can be found in [1].

In this work, attention is pointed out on masonry vaults, that have a wide diffusion in 
historical buildings. Their structural behavior has been studied for a long time [2,3], but even if a great number of numerical applications has been developed [4], their mechanical behavior is still not fully understood.

Among the different methods that may be found in literature, Limit Analysis is particularly fit to study the collapse behavior of masonry structure [5,6,7]. It is a very effective method for a fast and reliable evaluation of the structural safety of masonry vaults, whose equilibrium is guaranteed when the thrust surface is entirely enclosed within the vault thickness [8]. In literature, both classic upper bound $[9,10,11,12]$ and lower bound theorems $[13,14,15]$ have been applied to study equilibrium and to evaluate failure mechanisms.

Being the behavior of masonry vaults intimately related to their shape, an exact geometric representation is essential in the evaluation of their load-bearing capacity [16,17]. With this aim, geometric reconstructions obtained from point cloud data derived by photogrammetry and/or terrestrial laser scanner may be very useful [18] to provide information both on metrics and on the health status, highlighting cracking and deviation from vertical or horizontal directions $[19,20]$ or from ideal shape, assessed through comparison with parametric [21] or non-parametric models [22].

Here, attention is focused on masonry lowered sail vaults built around the middle of the $19^{\text {th }}$ century with different brick patterns (Figure 1(a)). These vaults have a great diffusion in South Sardinia, and particularly in Cagliari area, but only few studies about them have been carried out, up to now [23]. A series of rigorous laser scanner surveys have been performed on these vaults, in order to obtain the effective geometry both at macro-level, the vault shape, and at micro-level, the brick patterns. A picture of the obtained geometrical outline is reported in
(Figure 1(b)).
A NURBS-based upper bound linit analysis annroach is adopted to study their collapse
behavior under vertical loads and subjected to differential vertical settlements. A prelinfinary
example of the proposed procedure is given by Grillanda et al.[24].

Register for free at https//www.scipedia.com to download the version without the watermark

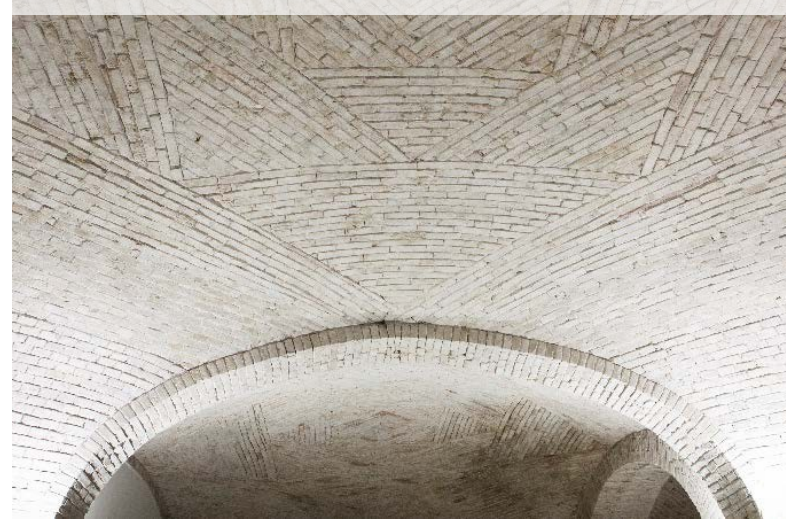

(a)

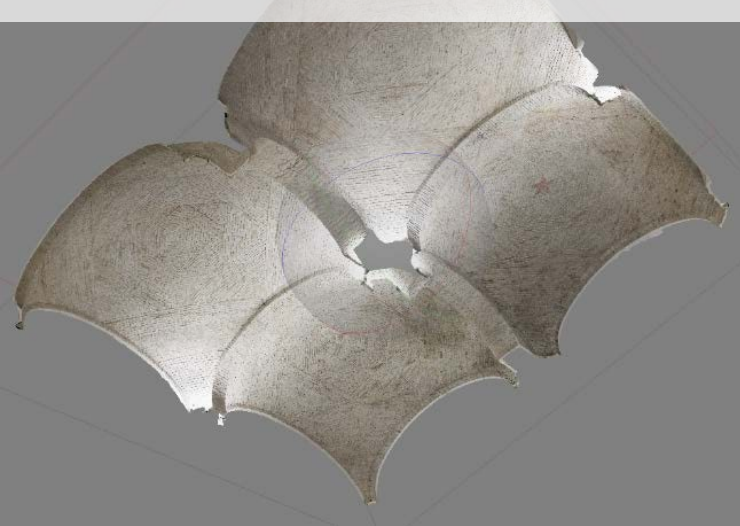

(b)

Figure 1. A typical lowered sail vault in Cagliari (a); geometry obtained by laser scanner survey (b). 


\section{METHOD: ADAPTIVE NURBS KINEMATIC APPROACH FOR LIMIT ANALYSIS AND STUDY OF SETTLEMENTS ON MASONRY VAULT}

For the geometric representation of masonry vaults, the NURBS geometry is one of the more suited modeling techniques. NURBS surfaces (Non-Uniform Rational B-Spline, [25]) are parametric surfaces built from a three-dimensional net of control points and rational B-spline basis functions (the so-called NURBS basis functions). A NURBS surface is defined as follow:

$$
s S(u, v)=\gtrless_{i i=0 j j=0}^{n} \boldsymbol{P Q}_{i, j, j}(u, v) \mathrm{B}_{i, i j j}
$$

in which: $\mathrm{u}, \mathrm{v}$ are coordinates in the standard parametric domain; $\mathrm{B}_{i i, j j}$ is a bidirectional net of control points; $\mathrm{n}, \mathrm{m}$ are the numbers of basis functions respectively along the $\mathrm{u}$ - and v-direction; $\mathrm{Ri}, \mathrm{j}$ are the NURBS basis functions, which are written as follows:

$$
R_{i, p}(\xi \xi)=\frac{N_{i, p}(\xi \xi) \cdot W_{i i}}{\sum_{i=1}^{n} N_{i, j}(\xi \xi) \cdot W_{i i}}
$$

where: $\Xi=\{\xi 1, \xi 2, \ldots, \xi(\mathrm{n}+\mathrm{p}+1)\}$ is a non-uniform knots vector; wi $\in \mathbb{R}$ are weight; Ni,p is the i-th B-Spline basis function of degree $p$.

NURBS surfaces are commonly adopted in the graphic representation of curved geometries. A masonry vault can be easily reproduced by using NURBS surfaces, and the obtained threedimensional model can In the MATLAB enviro partitioning the standar surfaces is defined: vault (Figure 2(c)). be defined. Starting by an initial mesh, mesh adj
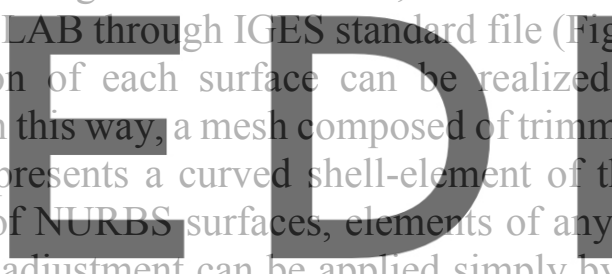

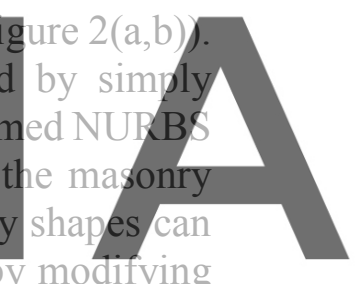
lines adopted in the subdivision of the standard parametric domain (e.g. moving intersection

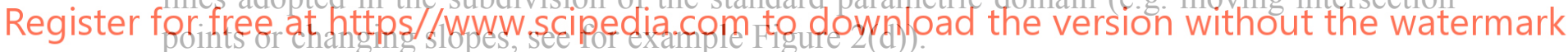

The trimmed surfaces composing the NURBS model of the vault are here idealized as rigid macro-biocks. In order to take into account non-linearities of masonry material, curved nonlinear interfaces will be defined on elements' edges. Each interface is discretized through points to which the local reference system is defined (Figure 3(a)). A rigid-plastic behavior, defined through a three-dimensional failure surface (typically a Mohr-Coulomb domain with tension cut-off and linear cap in compression, Figure 3(b)) and the associated plastic flow rule, is assigned at each point (we remand to previous works [26] for details on the mathematical formulation). According to this model, in which relative velocities jump can be observed at edges only, interfaces assume the meaning of possible fracture lines to which the mechanism takes place.

A procedure of upper bound limit analysis is adopted on this model. Dead (permanent) loads and live loads (depending on a load multiplier $\Gamma$ ) are defined. The multiplier $\Gamma$ associated to live loads is determined through the Principle of Virtual Powers, which is computed by means of the following linear programming problem: 


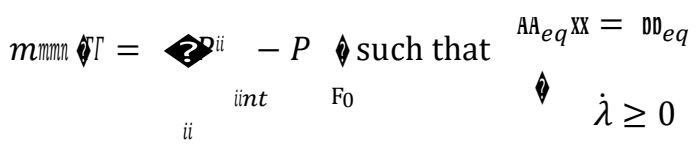

in which: $P_{i i n t}^{i i}$ is the internal power dissipated at the $\mathrm{i}$-th interface; $P_{\mathrm{F}}$ is the external power dissipated by dead loads; $\lambda$ are the non-negative plastic multipliers; $\mathbf{x x}$ is the vector of unknowns; $\mathrm{AA}_{e q}$ and $\mathrm{bb}_{e q}$ define the applied equality constraints (i.e. geometrical, compatibility equality constraints and the normality condition).

By solving this linear programming problem, a mechanism and a load multiplier associated with the adopted mesh, i.e. the hypothesized position of fracture lines, are found. In order to optimize the live load multiplier and obtain the real collapse mechanism (according to the kinematic theorem of limit analysis), a procedure of mesh adaptation based on a Genetic Algorithm (GA) is applied (see Figure 4). For details and applications of this adaptive upper bound limit analysis, we refer to $[24,27,28,29]$.

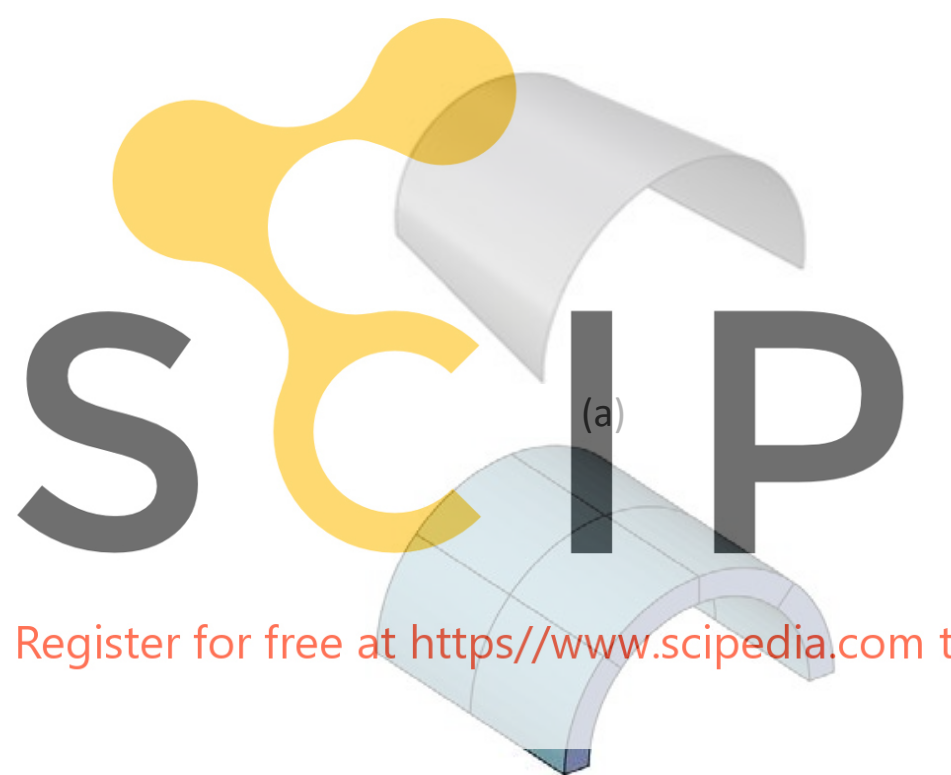

(c)

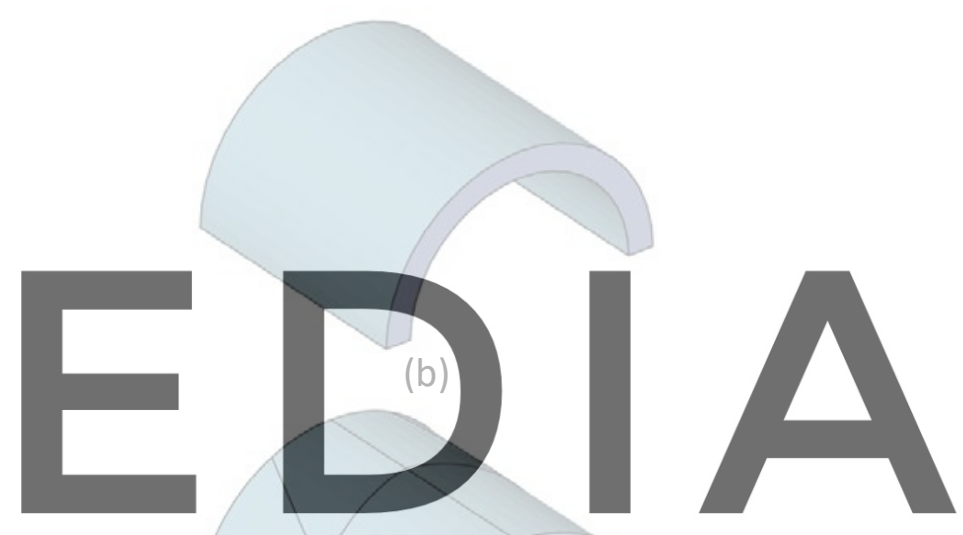

el generation: (a) NURBS surface in Rhinoceros, (b) NURBS model in MATLAB and its discretization by means of (c) a regular and (d) an irregular mesh.

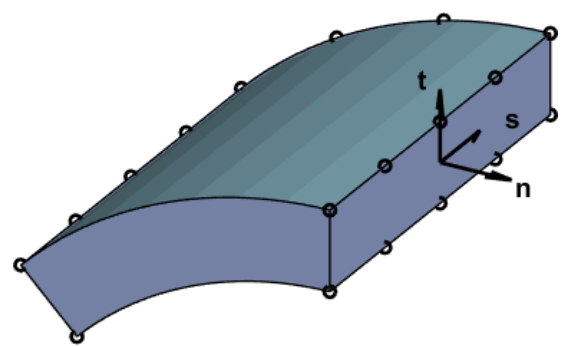

(a)

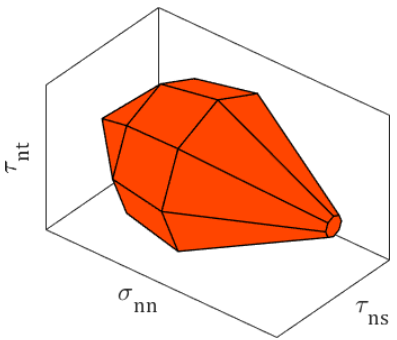

(b)

Figure 3. Representation of masonry behavior: masonry-masonry interface and corresponding local reference system (a), and linearized 3D representation of the failure domain (b). 


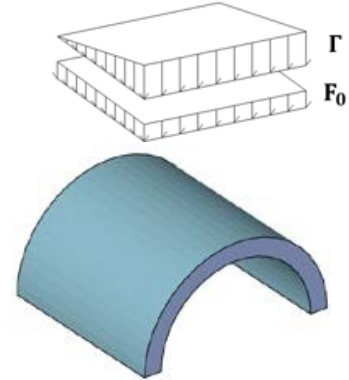

(a)

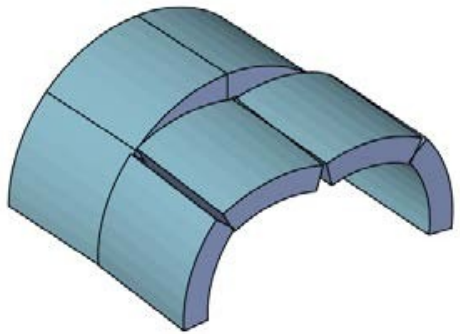

(b)

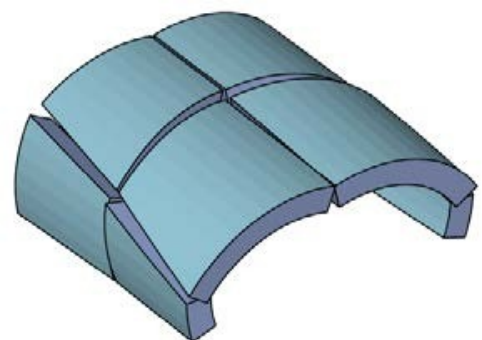

(c)

Figure 4. Mesh adaptation procedure: (a) example of load configuration, (b) mechanism associated with the regular mesh, (c) collapse mechanism obtained through GA optimization.

A similar formulation can be adopted in the study of masonry vaults subjected to settlements. Suppose a certain displacement field $\hat{u}_{00}$ is imposed at the external edges of the masonry vault. By discretizing through rigid elements, the crack pattern and displacements induced on the structure can be deduced by solving a unilateral contact problem in which the external work is maximized (see [30]) or, alternatively, the constraint reaction to the settlements is minimized (in agreement with the more recent formulation presented by some of the Authors [31]). If the internal plastic dissipation is assumed on interfaces, the problem can be solved through the Principle of Virtual Work, which can be written according to the following linear programming:
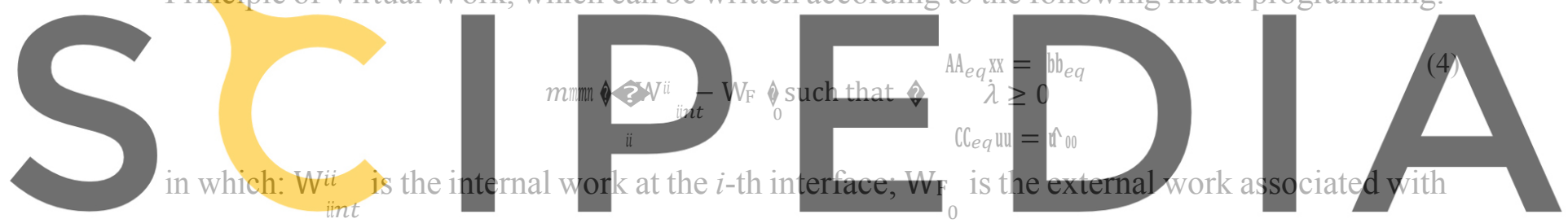

the applied loads; un is the vector of all displacements of the centroids; CCeq define the equality

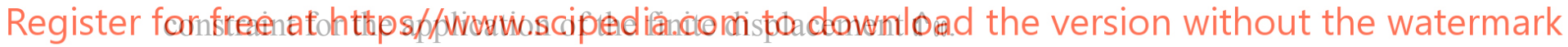

Therefore, the same adaptive kinematic approach is here applied for the study of the influence of settlements on the masonry vault. By using the same NURBS discretization and the same GA-mesh adaptation, the optimized crack pattern deriving from a defined settlement is properly deduced.

\section{NUMERICAL ANALYSES}

The structural system involves four vaults (see Figure 1(b)), each one supported on its whole perimeter: the two internal edges between the vaults are supported by masonry arches, while the external edges are supported by masonry walls. In the work, a single vault is analyzed. Arches and external walls are not directly modelled, but they are considered by means of appropriate boundary conditions. The vaults are made by a single brick layer, resulting in a thickness value of about $12 \mathrm{~cm}$ along the whole surfaces. The peculiarity of these vaults is the presence of several bricks' arrangements: the vault can be divided in triangular portions characterized by a different orientation of the masonry texture (see Figure 1(a)).

The model has been realized starting from the laser scanner survey: horizontal and vertical 
sections of the vault have been extracted (Figure 5 (a)) and then imported in the CAD software Rhinoceros, where an assembly of NURBS surfaces has been created (Figure 5 (b)). A different NURBS has been adopted for each triangular portion of vault: different properties have been assigned to each surface in order to take into account the specific orientation of the masonry texture in the limit analysis. The edge of surfaces between the different triangular portions correspond to possible fracture lines that may develop under vertical loads or due to settlements. The assemble of surfaces has been imported into the MATLAB environment, assigning thickness properties, in order to realize the NURBS model (Figure 5(c)).

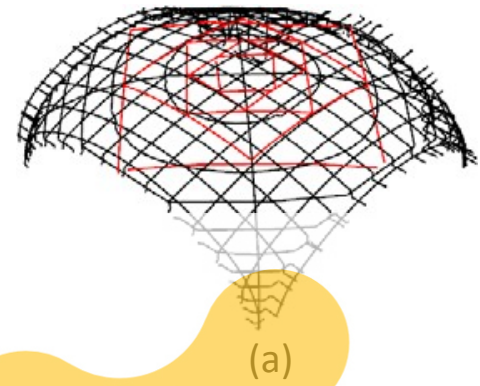

Figure 5. Construction of the NURBS model of the single vault: (a) section lines, (b) assembly of NURBS surfaces in Rhinoceros and (c) obtained NURBS model in MATLAB.

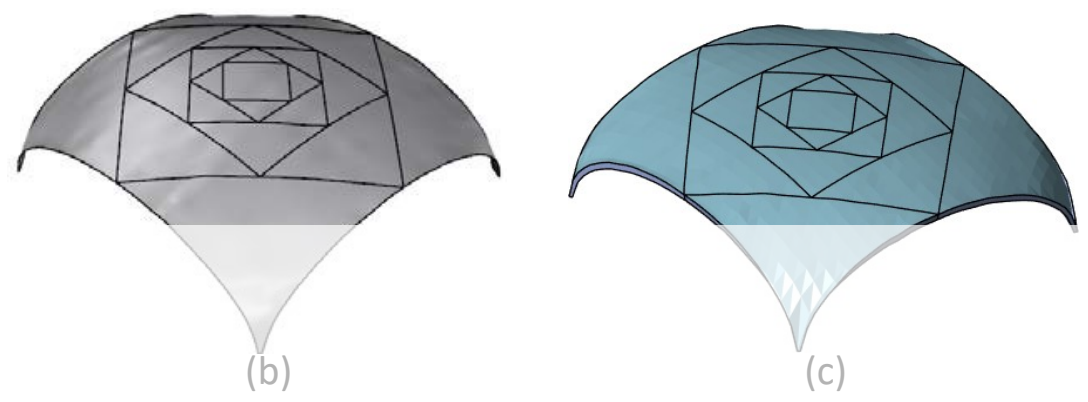

In the first step of analysis cracks may develop only along the initial NURBS surfaces of the model, corresponding different orientation of bearing capacity of the ( 1).
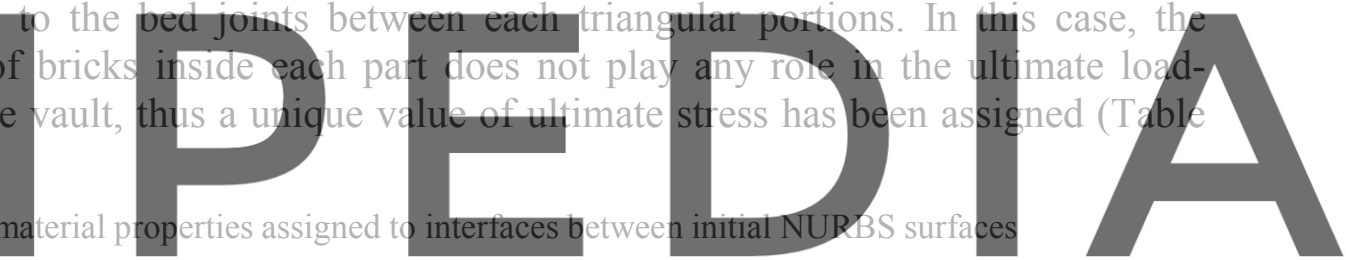

Property Value

Register for free at https//wwW.scipedifa.eonh tovdównload the version without the watermark

\begin{tabular}{cc}
\hline Ultimate tensile strength $[\mathrm{MPa}]$ & 0.2 \\
\hline Ultimate compression strength $[\mathrm{MPa}]$ & 2.6 \\
\hline Cohesion $[\mathrm{MPa}]$ & $\mathrm{ft}$ \\
\hline Friction angle $\left[{ }^{\circ}\right]$ & 30 \\
\hline
\end{tabular}

Being the hypothesis of failure only along the triangular portions too simplistic, in the second step of analysis each triangular portions has been subdivided into smaller elements (see Figure 6(a)) chosen taking into account the shape of each surface. The refined mesh is reported in Figure 6(b). In this case, bricks orientation is accounted adopting appropriate values of ultimate stress. A simplified orthotropic model for masonry [32] is adopted: different properties have been assigned to direction 1 , parallel to bed joints, and direction 2, orthogonal to the first one (Table 2).

Finally, a third step of analysis is performed applying the mesh adaptation through GA: the refined mesh is adaptively modified in order to find the minimum value of the live load multiplier. In this case, if the orthogonal normal vector is directed along an intermediate direction between 1 and 2, the ultimate stress values are evaluated according to the two main components of the normal vector. 
Two analyses are performed: under vertical loads and applying differential settlements.

Table 2: Material properties assigned to interfaces in the refined mesh

\begin{tabular}{cc}
\hline Property & Value \\
\hline Specific weight $[\mathrm{kN} / \mathrm{m} 3]$ & 18 \\
\hline Ultimate tensile strength - direction $1[\mathrm{MPa}]$ & 0.4 \\
\hline Ultimate tensile strength - direction $2[\mathrm{MPa}]$ & 0.2 \\
\hline Ultimate compression strength - direction $1[\mathrm{MPa}]$ & 5.2 \\
\hline Ultimate compression strength - direction $2[\mathrm{MPa}]$ & 2.6 \\
\hline Cohesion $[\mathrm{MPa}]$ & $\mathrm{ft}$ \\
\hline Friction angle $\left[{ }^{\circ}\right]$ & 30 \\
\hline
\end{tabular}

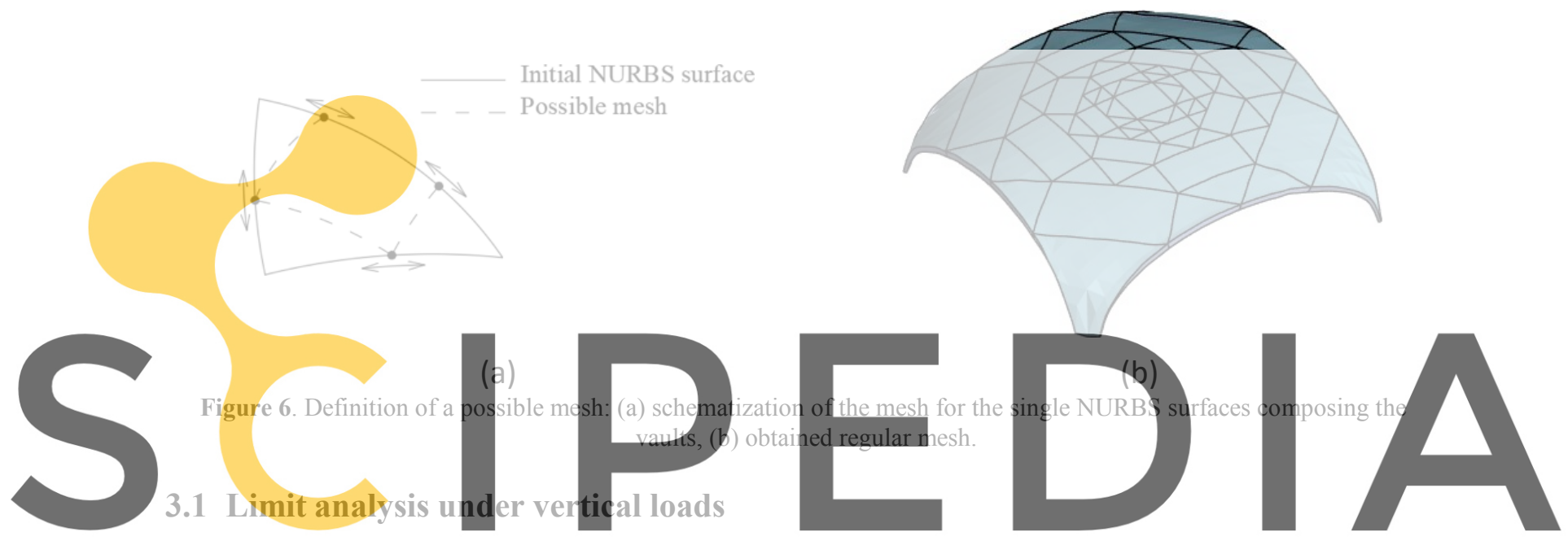

Two vertical load cases have been considered: Load Case 1 (LC1), in which live load

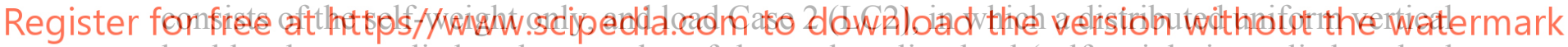
load has been applied at the extrados of the vault as live load (self-weight is applied as dead load, so it is not affected by the load multiplier). For each load case, a live load multiplier $\Gamma$ is found. If the final load multiplier is higher than one, as expected, the vault is definitely safe under self-weight (LC1) and under increasing loads (LC2). In order to better compare the results obtained applying the two load cases, the load multiplier obtained in LC2 has been normalized relatively to the total weight of the vault. Results of the three steps of analyses for both load cases, in terms of live load multiplier and collapse mechanism, are reported in the following figures.

In Figure 7 analyses are performed on the initial mesh: live load multipliers $\Gamma$ are equal to 38.1 and 35.5 respectively for LC1 and LC2. It can be observed that there are no substantial differences between the two collapse mechanisms. The value of the multiplier of LC1 is higher than the one of LC2, and in both cases $\Gamma$ is considerably higher than one: because of the lowered shape of the vault, crushing assumes a fundamental role in comparison with tensile and shear failures.

A similar trend may be observed in the second step of analysis, reported in Figure 8 . The adoption of a refined mesh allows obtaining lower values of the load multipliers $\Gamma$, equal to 
33.4 and 30.7 respectively for LC1 and LC2. Also in this case, since failure may occur only between the interfaces of the refined mesh, the two mechanisms of collapse are almost the same.

Figure 9 shows the results of the third step of analysis: the mesh adaptation through GA allows to finally obtain the minimum load multipliers, equal to 32.6 and 30.0 respectively for LC1 and LC2. Moreover, in this case, the two mechanisms of collapse obtained by LC1 and LC2 are different.
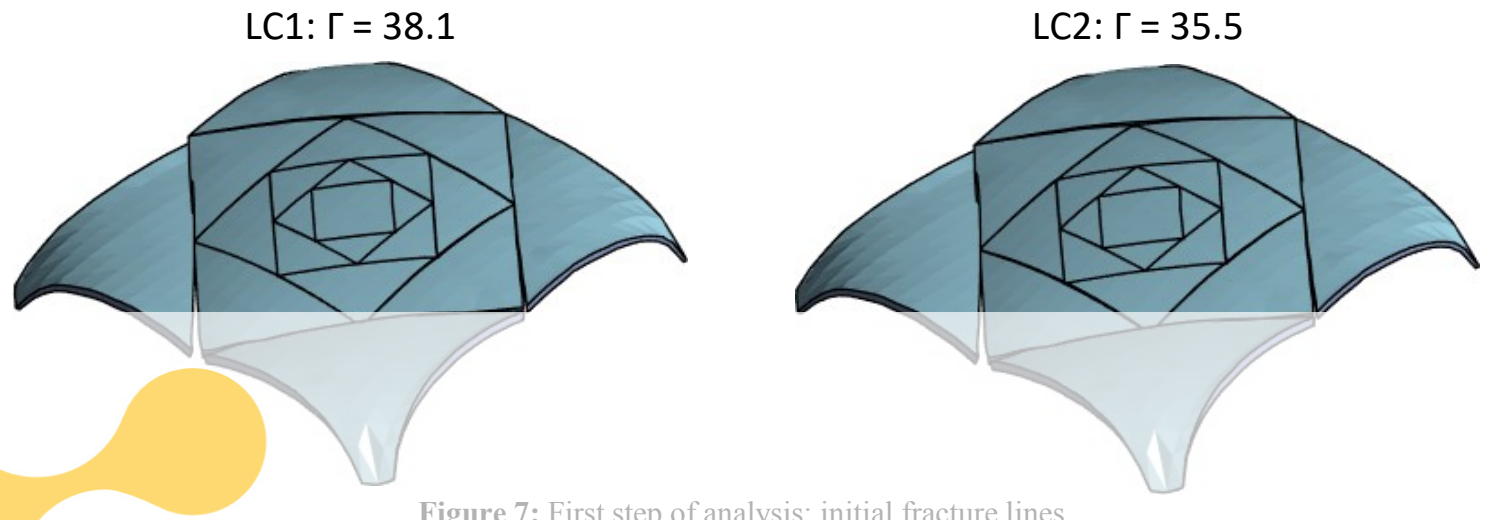

Figure 7: First step of analysis: initial fracture lines.
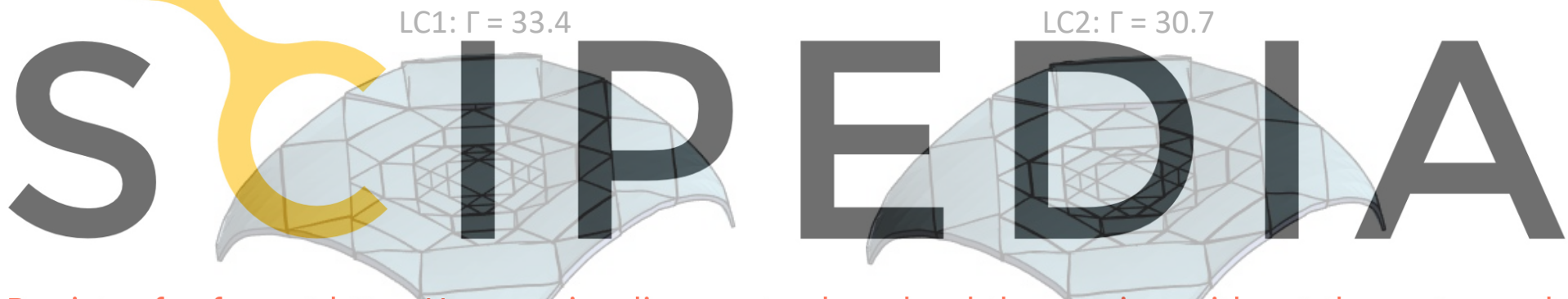

Register for free at https/Xwww.scipedia.com to download the version without the watermark

Figure 8: Second step of analyses: refined mesh.
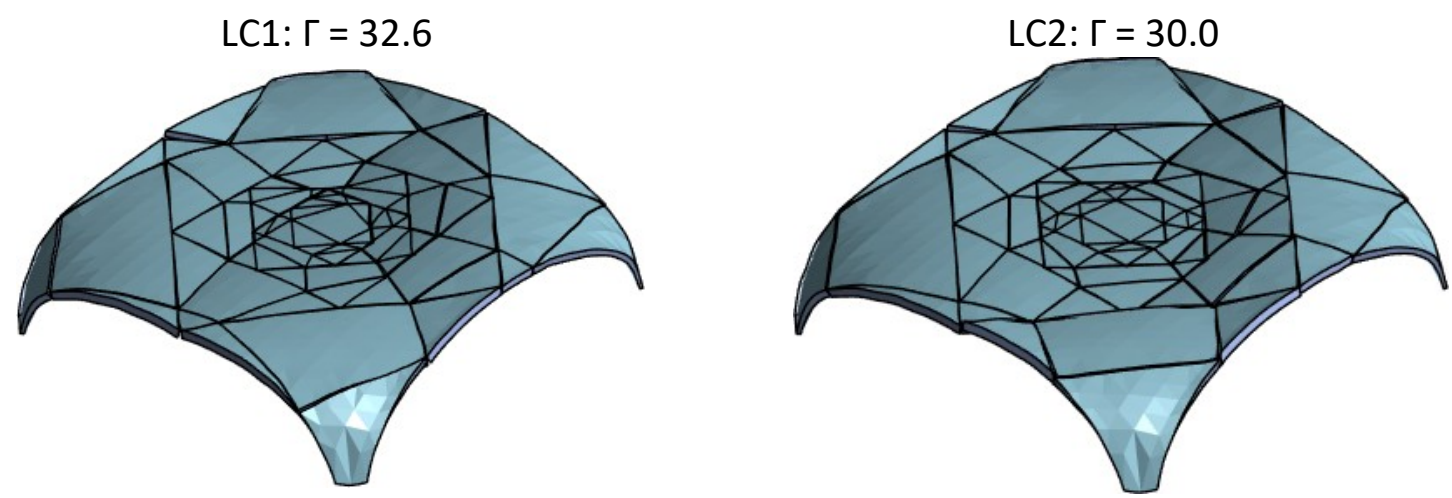

Figure 9: Third step of analyses: mesh adaptation 


\subsection{Limit analysis whit differential vertical settlements}

The crack pattern deriving from an imposed settlement has been determined through the presented procedure. A vertical settlement has been applied along one of the four external edges of the vault (see Figure 10 (a)), as a representation of vertical displacement of the supporting walls. The applied displacement is equal to $1 \mathrm{~cm}$ for the whole edge. The same initial mesh has been assumed for each triangular portion of the vault. The final crack pattern and the deformed structure (scaled according to a factor equal to 50) are depicted in Figure 10 (b-d).

As it can be noted, the cracks are mainly localized on the half of the vault subjected to the settlements. Moreover, it is worth noting that the main diagonal cracks follow the mortar joints between the different triangular portions of the vault. This is the natural consequence of the lower resistance parameters assigned to interfaces corresponding to mortar joints.

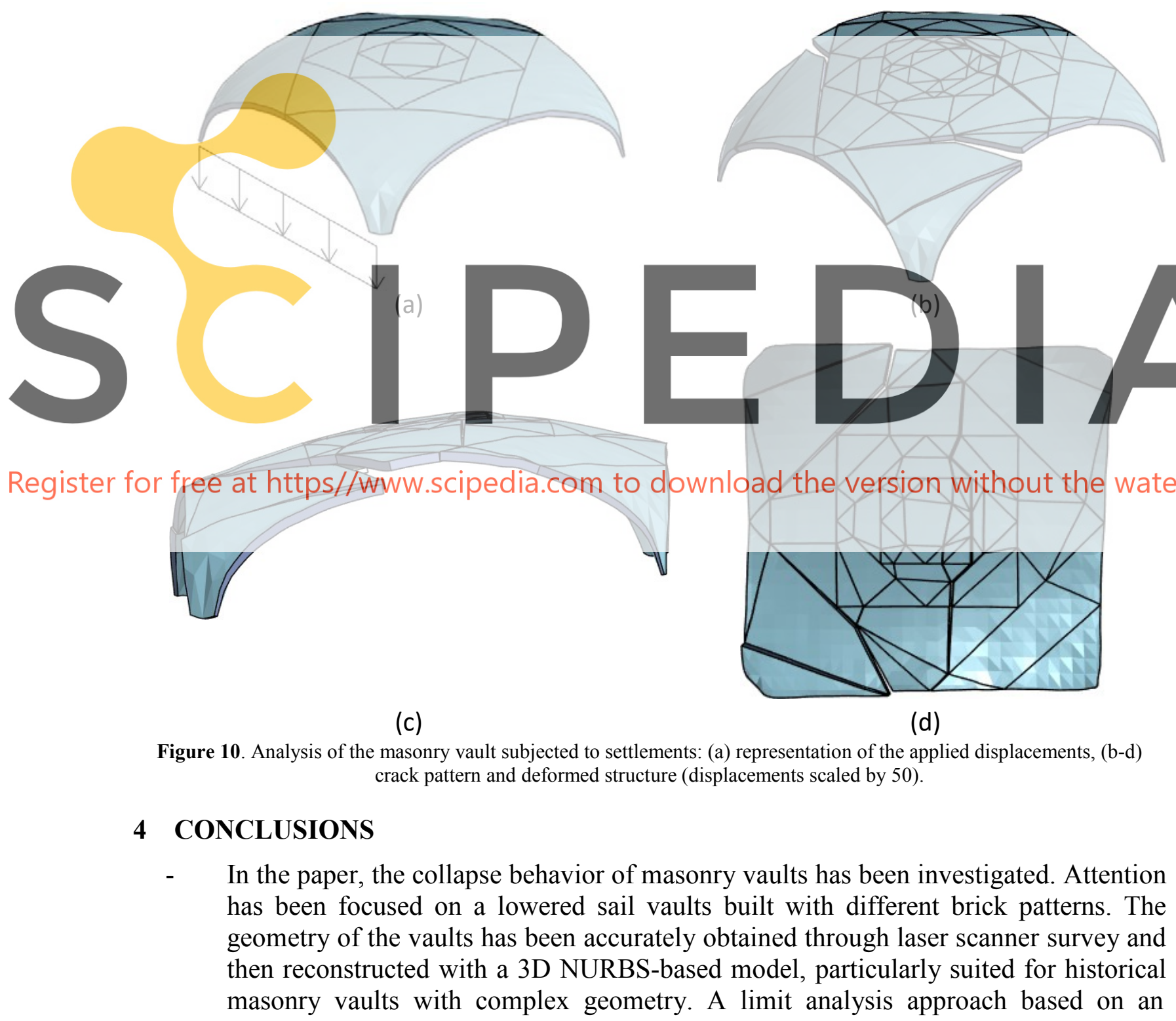


adaptive NURBS modeling coupled with a genetic algorithm has been performed to obtain the ultimate load of the structure and the associated collapse mechanisms for two different load conditions and in case of differential settlements.

- The use of laser scanner surveys and the adoption of 3D NURBS allow to describe the exact geometry of the vaults. This aspect is essential in the evaluation of their loadbearing capacity, being their behavior intimately related to their shape.

- $\quad$ Because of the lowered shape of the vault, crushing assumes a fundamental role in comparison with tensile and shear failures.

- Differential settlements must be studied: they may be a serious hazard for this structural typology.

- The role played by bricks arrangements must be considered in order to obtain reliable mechanisms of collapse.

- The proposed procedure provides fast and reliable assessment of the collapse behavior of masonry vaults.

\section{REFERENCES}

[1] D’Altri, A., Sarhosis, V., Milani, G., Rots, J., Cattari, S., Lagomarsino, S., et al. 2019. Modeling strategies for the computational analysis of unreinforced masonry structures: Review and classification. Arch. Comput. Method. Eng doi:10.1007/s11831-019-09351-x

[2] Boothby, T. E. 2001. Analysis of masonry arches and vaults. Progress in Structural Engineering and materials, 3(3)-246-256.
Lucchesi, M., Padovani, C., Pasquinelli, G. \& Zani N. 2007.
constitutive model and numerical analysis. J. Mech. Mater. St
Tralli, A., Alessandri, C. \& Milani, G. 2014. Computational Met of Recent Results. The Open Civil Engineering Journal,
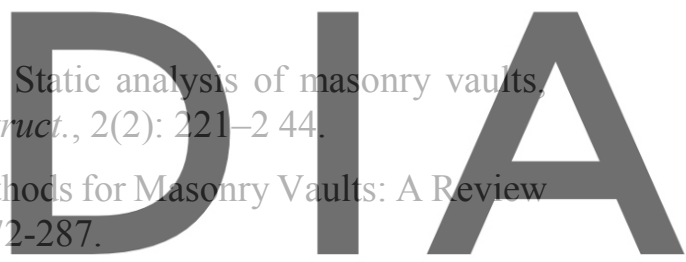

[5] Valente, M., Milani, G., Grande, E., \& Formisano, A. 2019. Historical masonry building aggregates:

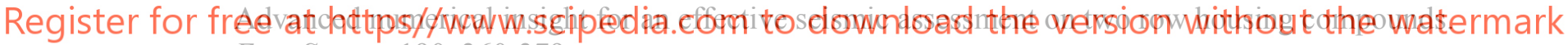
Eng. Struct., 190, 360-379.

[6] Valente, M., \& Milani, G. 2019. Earthquake-induced damage assessment and partial failure mechanisms of an italian medieval castle. Eng. Fail. Anal., 99, 292-309.

[7] Pepe, M., Pingaro, M., Trovalusci, P., Reccia, E., \& Leonetti, L. 2020. Micromodels for the in-plane failure analysis of masonry walls: Limit analysis, FEM and FEM/DEM approaches. Frattura ed Integrita Strutturale, 14(51), 504-516

[8] Heyman, J. 1969. The safety of masonry arches, Int. J. Mech. Sci., 11 (4): 363-385,

[9] D'Ayala, D. \& Casapulla, C. 2001. Limit state analysis of hemispherical domes with finite friction. In Structural Analysis of Historical Constructions, Guimarães (Portugal), 2001.

[10] Milani, E., Milani, G. \& Tralli, A. 2008. Limit analysis of ma-sonry vaults by means of curved shell finite elements and homogenization, Int. J. Solids Struct., 45: 5258-5288, 2008.

[11] Pavlovic, M., Reccia, E. \& Cecchi, A. 2016. A procedure to in-vestigate the collapse behavior of masonry domes: some meaningful cases. Int. J. Archit. Herit., 10(1): 67-83.

[12] Rossi, M., Calderini, C., Di Napoli, B., Cascini, L., \& Portioli, F. 2020. Structural analysis of masonry vaulted staircases through rigid block limit analysis. Structures, 23, 180-190. 
doi:10.1016/j.istruc.2019.10.015

[13] O’Dwyer, D. 1999. Funicular analysis of masonry vaults, Comp. Struct., 73(1-5): pp. 187-197.

[14] Block, P. \& Ochserdorf, J.A. 2007. Thrust network analysis: a new methodology for threedimensional equilibrium, J. IASS, 48(3): 167-173.

[15] Angelillo, M, Babilio, E. \& Fortunato, A. 2013. Singular stress fields for masonry-like vaults. Continuum Mech. Thermod., 25: 423-441.

[16] Cazzani, A., Malagù, M. \& Turco, E. 2016. Isogeometric anal-ysis: a powerful numerical tool for the elastic analysis of historical masonry arches, Continuum Mech. Thermodyn, 28: 139-156.

[17] Chiozzi, A., Malagù, M., Tralli, A. \& Cazzani A. 2016. Arch-NURBS: NURBS-Based Tool for the Structural Safety As-sessment of Masonry Arches in MATLAB, J. Comput. Civ. Eng., 30(2): \# 04015010-1-11.

[18] Schueremans, L. \& Van Genechten, B. 2009. The use of 3D-laser scanning in assessing the safety of masonry vaults. A case study on the church of Saint-Jacobs. Optics Lasers Eng., 47: 329-335.

[19] Castellazzi, G., D’Altri, A. M., de Miranda, S. \& Ubertini, F. 2017. An innovative numerical modeling strategy for the structural analysis of historical monumental buildings, Eng. Struct., 132: 229-248.

[20] Napolitano, R. \& Glisic, B. 2019. Methodology for diagnosing crack patterns in masonry structures using photogramme-try and distinct element modeling, Eng. Struct., 181: 519-528.

[21] Argiolas, R., Cazzani, A., Reccia, E. \& Bagnolo,V. 2019. From LIDAR data towards HBIM for structural evaluation, IS-PRS Archives, 42: 125-132.

[22] Armesto, J., Roca-Pardiñas, J., Lorenzo, H. \& Arias, P. 2010. Modelling masonry arches shape using terrestrial laser scanning data and nonparametric methods, Eng. Struct., 32(2): 607-615.

[23] Cazzani, A., Grillanda, N., Milani, G., Pintus, V. \& Reccia, E. Numerical insights on the structural assessment of typical historical masonry vaults of Cagliari, in Proceedings of 17th International Brick and Block Masonry Conference - 17th IB2MaC 2020, submitted

[24] N. Grillanda, A. Chiozzi, F. Bondi, A. Tralli, F. Manconi, F. Stochino, and A. Cazzani. Numerical insights on the structural assessment of historical masonry stellar vaults: The case of Santa Maria del Monte in Cagliari, Continuum Mech. Thermodyn., doi:10.1007/s00161-019-00752-8

[25] Piegl L \& Tiller W. The NURBS Book. Berlin: Springer; 1995.

[26] Chiozzi A, Milani G, Tralli A. 2017. A Genetic Algorithm NURBS-based new approach for fast kinematic limit analysis of masonry vaults. Comput Struct; 182:187-204.

[27] Chiozzi A, Milani G, Grillanda N, Tralli A. 2003. Fast and reliable limit analysis approach for the structural assessment of FRP-reinforced masonry arches, Key Eng. Mater., 747:196-203.

[28] Grillanda N, Chiozzi A, Milani G, Tralli A. 2019. Collapse behavior of masonry domes under seismic loads: an adaptive NURBS kinematic limit analysis approach. Eng. Struct., 200: 109517.

[29] Grillanda N, Chiozzi A, Milani G, Tralli A. 2019. On Collapse Behavior of Reinforced Masonry Domes under Seismic Loads. Key Eng. Mater., 817:275-82.

[30] Iannuzzo, A., Angelillo, M., De Chiara, E., De Guglielmo, F., De Serio, F., Ribera, F., et al. 2108. Modelling the cracks produced by settlements in masonry structures, Meccanica, 53:1857-73.

[31] Tralli, A., Chiozzi, A., Grillanda, N., \& Milani, G. 2109. Masonry structures in the presence of 
foundation settlements and unilateral contact problems. Int. J. Solids Struct.. doi:10.1016/j.ijsolstr.2019.12.005.

[32] Milani, G., \& Taliercio, A. (2015). In-plane failure surfaces for masonry with joints of finite thickness estimated by a method of cells-type approach. Comp. Struct., 150, 34-51 